\title{
Sejarah Pemikiran Ekonomi Islam Pada Masa Daulah Bani Umayyah dan Bani Abbasiyah
}

\author{
Muhammad Nurul Huda \\ Institut Agama Islam Negri Ponorogo \\ Email: Anhuda92@gmail.com
}

\begin{abstract}
This article is the result of an analysis of economic history in the past which is to answer economic problems during the Umayyad and Abasiyyah Daulah, economic activities carried out during the Daulah Bani Umayyah and Bani Abasiyyah. This research uses the Historical Method by using secondary sources originating from December. which literature has been previously reviewed and analyzed. While in the approach the writer uses a historical approach. This approach is used by the author in order to reveal the economic problems of the Umayyad and Abasiyyah Bani. From the research results, it can be seen that the development of Islamic economics in the Umayyad and Abbasid dynasties was an economic policy formed based on the ijtihad of the fuqoha and ulama as a consequence of the increasingly distant time span between the Prophet's life and the reign. The abbasiyah caliph or the dynasty of the children of the abbot, as said to continue the rule of the Umayyad dynasty. His power lasted a long time. During the Abbasiyah dynasty in power where the patterns of government applied varied according to political, social and cultural changes.
\end{abstract}

\section{Keywords : Economy, Caliph, Islam}

\begin{abstract}
Abstrak
Artikel ini adalah hasil analisis sejarah ekonomi pada masa lampau yang mana untuk menjawab permasalahan ekonomi pada masa Daulah Bani Umayyah dan Bani Abasiyyah, aktivitas ekonomi yang dilakukan pada masa Daulah Bani Umayyah dan Bani Abasiyyah, Penelitian ini menggunakan Metode Historis dengan menggunakan sumber sekunder yang berasal darisember kepustakaan yang mana telah ditelaah dan dianalisis sebelumnya. Sementara dalam pendekatan penulis menggunakan pendekatan historis. Pendekatan ini diigunakan penulis agar agar dapat mengungkapkan permasalahan ekonomi pada Masa Bani Umayyah dan Bani Abasiyyah. Dari hasil penelitian dapat diketahui bahwa Perkembangan ekonomi islam pada Dinasti Umayyah dan Abbasiyah merupakan kebijakan ekonomi banyak dibentuk berdasarkan ijtihad para fuqoha dan ulama sebagai konsekuensi
\end{abstract}


semakin jauhnya rentang waktu antara zaman kehidupan Rasulullah dan masa pemerintahan tersebut. Khalifah abbasiyah atau kekuasaan dinasti bani abbas, sebagai mana disebutkan melanjutkan kekuasaan dinasti bani umayah. Kekuasaannya berlangsung rentang waktu yang panjang . selama dinasti bani abbasiyah berkuasa dimana pola pemerintahan yang diterapkan berbeda-beda sesuain dengan perubahan politik, sosial, dan budaya.

Kata kunci : Ekonomi, Khalifah, Islam

\section{PENDAHULUAN}

Perekonomian adalah merupakan salah satu unsur terpenting dalam memperlancar proses pembangunan suatu negara. Sebab merosotnya perekonomian suatu negara akan berpengaruh terhadap proses pelaksanaan pembangunan yang akan dilakukan. Dalam kesempatan ini, kami akan membahas mengenai perkembangan ekonomi pada masa Daulah Abbasiyah dan Daulah Umayyah. Yang didalamnya membahas mengenai perkembangan dan pertumbuhan pada kedua masa daulah tersebut. Serta memaparkan bagaimana sistem pemerintahan pada setiap khalifahnya. Salah satu contoh Pada masa pemerintahan Abdul Malik, perkembangan perdagangan dan perekonomian, teraturnya pengelolaan pendapatan negara yang didukung oleh keamanan dan ketertiban yang terjamin telah membawa masyarakatnya pada tingkat kemakmuran.

Maka dari itu diperlukan kajian yang mendalam mengenai ekonomi syariah (ekonomi islam) ini. Berawal dari sinilah penyusun membuat makalah ini, dengan tujuan agar memahami bagaimana sejarah pemikiran ekonomi yang dulu pernah berjaya dan dapat menjadi jawaban atas gelisahan yang ada pada masa kejayaan islam. Oleh karena itu penyusun menyusun laporan ini, dengan kajian khusus pada masa dinasti umayyah dan abbasiyah agar dapat bermanfaat untuk perkembangan ekonomi syariah pada masa yang akan datang. 


\section{METODE PENELITIAN}

Metode pengumpulan data yang digunakan dalam penyusunan artikel ini ialah studi pustaka (Absor, 2019). Caranya adalah dengan mengambil data dari beberapa buku yang bersumber dari kepustakaan, yang selanjutnya akan ditelaah dan dianalisis guna untuk memperoleh hasil yang baik. Metode ini disebut dengan metode dokumentasi.

\section{HASIL DAN PEMBAHASAN}

\section{A. Tradisi Dan Praktek Ekonomi Masa Daulah Umayah (41- 132h/ 661-750m)}

Perekonomian adalah merupakan salah satu unsur terpenting dalam memperlancar proses pembangunan suatu negara. Sebab merosotnya perekonomian suatu negara akan berpengaruh terhadap proses pelaksanaan pembangunan yang akan dilakukan. Cari Brockelmann menegaskan bahwa: "Pada tahun 693 khalifah Abdul Malik secara bulat menetapkan untuk mencetak uang sendiri di damaskus. Sementara itu Hajjaj pada tahun berikutnya melakukan hal yang sama. Akibatnya masyarakat Arab sudah mulai mengenal sistem perhitungan. Ide ini juga diterima di Yaman, Siria, dan Iraq. Kebijaksanaan yang dikeluarkan oleh Khalifah Abdul Malik tersebut, sangat berpengaruh terhadap perekonomian dinasti itu. Sebab kita melihat, sebelum diberlakukannya kebijakan ini mata uang yang beredar sebagai alat tukar adalah mata uang Roma dan mata uang Persia yaitu dirham (drachma) dan dinar (dinarius). Dengan tidak adanya mata uang sendiri tentu akan dapat mengurangi nilai-nilai persatuan dan kesatuan umat Islam di daerah yang demikian luasnya. Sehingga dapat dikatakan, secara implisit kebijaksanaan khalifah memiliki nilai-nilai esensial dalam mewujudkan persatuan dan kesatuan umat Islam dalam wilayah yang luas tersebut. Implikasi nilai-nilai persatuan dan kesatuan terhadap perekonomian pada masa itu (Dinasti Umayyah) adalah sangat penting. Sebab adanya persatuan dan kesatuan wilayah umat Islam yang luas tersebut akan menciptakan stabilitas keamanan yang terjamin. Dengan adanya stabilitas keamanan yang terjamin, maka lalu lintas perdagangan akan berjalan lancar, dengan lancarnya lalu lintass perdagangan, pada gilirannya akan meningkatkan perekonomiannya. 
Pada masa pemerintahan Abdul Malik, perkembangan perdagangan dan perekonomian, teraturnya pengelolaan pendapatan negara yang didukung oleh keamanan dan ketertiban yang terjamin telah membawa masyarakatnya pada tingakat kemakmuran. Realisasinya dapat kita lihat dari hasil penerimaaan pajak (kharaj) di wilayah syam saja, tercatat 1.730.000 dinar emas setahun. Kemakmuran masyarakat Bani Umayyah juga terlihat pada masa pemerintahan Umar ibn Abdul Aziz. Keadaan perekonomian pada masa pemerintahannya telah naik ke taraf yang menakjubkan. Semua literatur yang ada pada kita sekarang ini menguatkan bahwa kemiskinan, kemelaratan, dan kepapaan telah dapat diatasi pada masa pemerintahan khalifah ini.

kebijakan yang dilakukan oleh Umar ibn Abdul Aziz dalam implikasinya dengan perekonomian yaitu membuat aturanaturan mengenai takaran dan timbangan, dengan tujuan agar dapat membasmi pemalsuan dan kecurangan dalam pemakaian alat-alat tersebut. Bertitik tolak dari uraian di atas dapatlah dikatakan perkembangan perekonomian pada masa pemerintahan Dinasti Umayyah secara umum sudah mulai meningkat dibanding dengan masa sebelumnya. Meningkatnya perekonomian yang membawa kepada kemakmuran rakyat pada dinasti ini, sebenarnya tidak terlepas dari kebijaksanaankebijaksanaan yang dilakukan khalifah, di samping dukungan masyarakat terhadap kebijaksanaan-kebijaksanaan tersebut.

Naiknya Muawiyyah ke tampuk pemerintahan Islam merupakan awal kekuasaan Bani Umayyah. Sejak saat itu pula, pemerintahan Islam yang bersifat demokratis seperti yang telah dipraktekkan Rasulullah SAW dan khulafa arrasyidin berubah menjadi monachiheridetis (kerajaan turun menurun). Muawiyyah memperoleh kekuasaan melaului jalan kekerasan, diplomasi, dan tipu daya tidak melalui jalan musyawarah. Dalam menjalankan kekuasaannya, ia tetap menggunakan istilah khalifah yang diartikan sebagai penguasa yang diangkat oleh Allah. Sejak bani umayyah berkuasa, seorang khalifah tidak lagi harus seorang ahli hukum agama (fuqaha). Dinasti ini mulai memisahkan antara pemegang otoritas keagamaan dengan pemegang otoritas 


\section{JOURNAL OF SOCIAL SCIENCES \& HUMANITIES "ESTORIA" UNIVERSITAS INDRAPRASTA PGRI}

politik.urusan agama diserahkan kepada para ulama, sedangkan urusan politik diserahkan kepada para penguasa. Pada masa daulah ini, pusat penyelenggaraan administrasi pemerintahan berada di Damaskus, sedangkan pusat aktifitas keagamaan berada di Madinah (Zuhri, 1997).

Selama masa pemerintahan dinasti ini, telah terjadi pergeseran nilai-nilai kepemimpinan Islami yang sangat mengedepankan asas-asas musyawarah dan kebersamaan menjadi kepemimpinan otoriter. Keadaan tersebut memacu timbulnya hasrat sebagian besar khalifah Bani Umayyah untuk memanfaatkan kekuasaan sebagai sarana memperkaya diri dan keluarganya. Baitul Mal yang merupakan kantor perbendaharaan umat seakan menjadi milik pribadi para pangeran. Pada masa pemerintahan Bani Umayyah, terdapat dua macam Baitul Mal; umum dan khusus. Pendapatan Baitul Mal Umum diperuntukkan bagi seluruh masyarakat umum. Sedangkan Baitul Mal khusus diperuntukkan bagi para sultan dan keluarganya. Namun, dalam prakteknya, tidak jarang berbagai penyimpangan penyaluran harta Baitul Mal tersebut. Pengeluaran untuk kebutuhan para sultan, keluarga, dan para sahabat dekatnya banyak yang diambilkan dari kas Baitul Mal Umum. Begitu pula halnya dengan pengeluaran lainnya yang tidak berhubungan dengan kesejahteraan umat Islam secara keseluruhan. Dengan demikian telah terjadi disfungsi penggunaan dana Baitul Mal pada masa dinasti Bani Umayyah (Amalia, 2010).

\section{Khalifah Muawiyyah bin Abi Sofyan}

Pada masa pemerintahannya, khalifah Muawiyah bin Abi Sofyan mendirikan dinas beserta dengan berbagai fasilitasnya, menertibkan angkatan perang, mencetak mata uang, dan mengembangkan jabatan qadi (hakim) sebagai jabatan profesional. Selain itu, khalifah Muawiyyah bin Abi Sofyan menerapkan kebijakan pemberian gaji tetap kepada para tentara, pembentukan tentara profesional, serta pengembangan birokrasi, seperti fungsi pengumpulan pajak dan administrasi politik (Engineer, 1999).

\section{Khalifah Abdul Malik bin Marwan}

Pemikiran yang serius terhadap penertiban dan pengaturan uang dalam masyarakat Islam muncul di masa pemerintahan 
khalifah Abdul Malik bin Marwan. Hal ini dilatarbelakangi oleh permintaan pihak Romawi agar khalifah Abdul Malik bin Marwan menghapus kalimat Bismillahirrohmaanirrohiim dari mata uang yang berlaku pada khilafahnya. Pada saat itu, bangsa Romawi mengimpor dinar Islam dari Mesir. Akan tetapi, permintaan tersebut ditolaknya. Bahkan, khalifah Abdul Malik bin Marwan mencetak mata uang Islam tersendiri dengan tetap mencantumkan kalimat Bismillahirrohmanirrohim pada tahun $74 \mathrm{H}(659 \mathrm{M})$ dan menyebarkannya ke seluruh wilayah Islam seraya melarang pemakaian melakukan percetakan mata uang lain . ia juga menjatuhkan hukuman ta'zir kepada mereka yang melakukan percetakan mata uang di luar percetakan Negara. Selain itu ia juga melakukan berbagai pembenahan administrasi pemerintahan dan memberlakukan bahasa Arab sebagai bahasa resmi administrsi pemerintahan Islam (Amalia, 2010).

\section{Khalifah Umar bin Abdul Aziz}

Selama masa pemerintahannya, Umar bin Abdul Aziz menerapkan kembali ajaran Islam secara utuh menyeluruh . berbagai pembenahan dilakukannya di seluruh sektor kehidupan masyarakat tanpa pandang bulu. Langkah ini dimulai dari dirinya sendiri. Ketika diangkat sebagai khalifah, umar bin Abdul Aziz mengumpulkan rakyatnya dan mengumumkan serta menyerahkan seluruh harta kekayaan diri dan keluarganya yang tidak wajar kepada kaum muslimin melalui Baitul Mal, mulai dari tanah-tanah perkebunan di Maroko, berbagai tunjangan yang berada di Yamamah, Mukaedes, Jabal Wars, Yaman, dan fadak, hingga cincin pemberian Al-Walid. Selama berkuasa, ia juga tidak mengambil sesuatupun dari Baitul Mal, termasuk pendapatan fai yang telah menjadi haknya.

Pada masa pemerintahannya, khalifah Umar bin Abdul Aziz memprioritaskan pembangunan dalam negeri. Menurutnya, memperbaiki dan meningkatkan kesejahteraan negeri-negeri Islam adalah lebih baik dari pada menambah perluasan wilayah. Dalam rangka ini pula, ia menjaga hubungan baik dengan pihak oposisi dan memberikan hak kebebasan beribadah kepada penganut agama lain. 
Di dalam melakukan berbagai kebijakannya, khalifah Umar bin Abdul Aziz bersifat melindungi dan maningkatkan kemakmuran taraf hidup masyarakat secara keseluruhan. Ia mengurangi beban pajak yang dipungut dari kaum Nasrani, menghapus pajak terhadap kaum Muslimin, membuat aturan takaran dan timbangan, membasmi cukai dan kerja paksa, memperbaiki tanah pertanian, penggalian sumur-sumur, pembangunan jalan-jalan, pembuatan tempat-tempat penginapan para musaffir, dan menyantuni fakir miskin. Berbagai kebijakan ini berhasil meningkatkan taraf hidup masyarakat secara keseluruhan hingga tidak ada lagi yang mau menerima zakat (Amalia, 2010).

Salah satu bukti kesungguhanya dalam menegakkan keadilan, khalifah Umar bin Abdul Aziz pernah membelanjakan seluruh kekayaan Baitul Mal di Irak untuk membayar ganti rugi kepada orang-orang yang diperlakukan semena-mena oleh para penguasa sebelumnya. Karena tidak mencukupi, ia mengambil dari kekayaan Baitul Mal di Syam. Khalifah Umar bin Abdul Aziz juga menetapkan bahwa para pejabat diberi gaji 300 dinar dan dilarang melakukan berbagai pekerjaan sampingan. Selain itu, pajak yang dikenakan kepada non-muslim hanya berlaku pada tiga profesi, yaitu pedagang, petani dan tuan tanah.

Dalam bidang pertanian, khalifah Umar bin Abdul Aziz melarang penjualan tanah garapan agar tidak ada penguasa lahan. Ia memerintahkan amirnya untuk memanfaatkan semaksimal mungkin lahan pertanian yang ada. Dalam menetapkan sewa tanah, khalifah Umar bin Abdul Aziz menerapkan prinsip keadilan dan kemurahan hati. Ia melarang memungut sewa terhadap tanah yang tidak subur dan jika tanah tersebut subur, pengambilan sewa harus memperhatikan tingkat kesejahteraan hidup petani yang bersangkutan.

Lebih jauh, khalifah Umar bin Abdul Aziz menerapkan kebijakan otonomi daerah. Setiap wilayah Islam mempunyai wewenang untuk mengelola zakat dan pajak secara sendirisendiri dan tidak diharuskan menyerahkan upeti kepada pemerintah pusat. Bahkan sebaliknya, pemerintah pusat akan memberian bantuan subsidi kepada setiap wilayah Islam yang minim pendapat zakat dan pajaknya (Kholik, 2000: 126). Dengan demikian, masing-masing wilayah Islam diberi kekuasaan untuk mengelola kekayaannya. Jika terdapat surplus, khalifah Umar 
bin Abdul Aziz menyarankan agar wilayah tersebut memberikan bantuan kepada wilayah yang minim pendapatannya. Untuk menunjang hal ini, ia mengangkat Ibnu Jahdam sebagai amil shodaqoh yang bertugas menerima dan mendistribusikan hasil shodaqoh secara merata ke seluruh wilayah Islam.

Dalam mewujudkan negara yang adil dan makmur, khalifah Umar bin Abdul Aziz menjadikan jaminan sosial sebagai landasan pokok. Baginya, hak seseorang yang telah meninggal dunia tidak akan hilang karena akan tetap diberikan kepada ahli warisnya. Begitu pula hak para tahanan. Hal ini berlaku secara universal, tanpa membeda-bedakan apakah ia seorang muslim atau bukan. Ia juga mendirikan rumah makan khusus untuk para fakir miskin. Sementara itu, jika terdapat kelebihan harta setelah digunakan untuk memenuhi kebutuhan kaum muslimin, pendapatan Baitul Mal didistribusikan kepada orang-orang dzimmi. Tidak hanya itu, kaum dzimmi itu juga diberikan pinjaman tanah-tanah pertanian sebagai lahan pekerjaan mereka.

Khalifah Umar bin Abdul Aziz juga mengeluarkan kebijakan pembukaan jalur perdagangan bebas, baik di darat maupun diudara, sebagai upaya meningkatkan taraf kehidupan masyarakat. Pemerintah menghapus bea masuk dan menyediakan berbagai bahan kebutuhan sebanyak mungkin dengan harga yang terjangkau (Amelia, 2010:104). Pada masa pemerintahannya, sumber-sumber pemasukan negara berasal dari zakat, hasil rampasan perang, pajak penghasilan pertanian (pajak ini di awal pemerintahan Umar bin Abdul Aziz ditiadakan mengingat situasi ekonomi yang belum kondusif, setelah stabilitas perekonomian masyarakat membaik, pajak ini diterapkan), dan hasil pemberian ladangan kerja produktif kepada masyarakat luas.

Setelah masa pemerintahan Umar bin Abdul Aziz tersebut, kekuasaan Bani Umayyah berada di tangan Yazid bin Abdul Malik. Pada masa ini, kekacauan dalam kahidupan masyarakat mulai muncul kembali. Hal ini dipicu oleh kegandrungan sang khalifah dan para penggantinya terhadap kemewahan dan ketidak peduliaannya terhadap kesejahteraan rakyat. Akibatnya, 
muncul konfrontasi antara pemerintah dengan rakyatnya sendiri. Kerusuhan tersebut terus berlanjut hingga semakin memperkuat oposisi dan sebaliknya, memperlemah posisi sang khalifah. Akhirnya pihak oposisi berhasil menumbangkan Daulah Umayyah.

\section{B. Tradisi Dan Prakek Ekonomi Daulah Abbasiyah (132-656 H/750-1258 M)}

Bani Abbasiyah meraih tampuk kekuasaan Islam setelah berhasil menggulingkan pemerintahan dinas Bani Umayyah pada tahun $750 \mathrm{H}$. Para pendiri dinasti ini adalah keturunan al-Abbas, paman Nabi Muhammad SAW, sehingga khilafah tersebut dinakamakan khilafah Abbasiyah. Dinasti ini didirikan oleh Abdullah al-Saffah bin Muhammad bin Ali bin Abdullah bin Abbas (132-136H) (Amalia, 2010). Pada masa Daulah Bani Abbasiyah, pusat pemerintahan Islam dipindahkan dari Damaskus ke Baghdad. Dalam kurun waktu lebih dari lima abad dinasti ini berkuasa, pola pemerintahan yang diterapkan berbeda-beda sesuai dengan perubahan politik, sosial dan budaya. Berdasarkan hal ini, Ahmad Syalabi membagi membagi masa pemerintahan Bani Abbasiyah menjadi tiga periode, yaitu:

a) Periode pertama, berlangsung dari tahun $132 \mathrm{H}$ sampai 232 H. Pada periode ini, kekuasaan berada ditangan para khalifah secara penuh.

b) Periode kedua, berlangsung dari tahun $232 \mathrm{H}$ sampai $590 \mathrm{H}$. Pada periode ini kekuasaan politik berpindah dari tangan khalifah kepada golongan Turki $(232 \mathrm{H}-334 \mathrm{H})$, dan Bani Saljuk (447 H-590 H).

c) Periode ketiga, berlangsung dari tahun $590 \mathrm{H}$ sampai $656 \mathrm{H}$. Pada periode ini kekuasaan kembali di tangan khalifah, tetapi hanya di Baghdad dan sekitarnya.

Diantara periode-periode pemerintahannya tersebut, dinasti Abbasiyah mencapai masa keemasan pada periode pertama. Pada masa ini, secara politis, para khalifah benar-benar tokoh yang kuat dan merupakan pusat kekuasaan politik dan agama sekaligus. Di sisi lain, kemakmuran masyarakat mencapai puncaknya. Periode ini juga berhasil menyiapkan landasan bagi perkembangan filsafat dan ilmu pengetahuan dalam Islam. Karena Abdullah Al-Saffah hanya memerintah dalam waktu yang singkat, pembina yang sesungguhnya dan Daulah Abbsiyah adalah Abu Ja'far Al-Manshur (136-148 H). Pada masa 
pemerintahannya, khalifah Al-Manshur lebih banyak melakukan konsolidasi dan penertiban administrasi birokrasi. Ia berusaha meletakkan dasar-dasar pemerintahan Daulah Abbasiyah. Pusat pemerintahan yang pada mulanya berada Hasyimiyah dipindahkan ke kota Baghdad yang baru dibangunnya. Ia menciptakan tradisi baru dibidang pemerintahan dengan mengangkat seorang wazir sebagai koordinator departemen. Khalifah Al-Manshur juga membentuk lembaga protokol negara, sekretaris negara, dan kepolisian negara, serta membenahi angkatan bersenjata dan membentuk lembaga kehakiman negara. Peranan jawatan pos semakin ditingkatkan dengan tambahan tugas dapat berjalan dengan lancar dan melaporkan perilaku gubernur setempat kepada khalifah.

Pada awal pemerintahan khalifah al-Manshur, perbendaharaan negara dapat dikatakan tidak ada karena khalifah sebelumnya, al-Saffah, banyak menggunakan dana Baitul Mal untuk diberikan kepada para sahabat dan tentara demi mengukuhkan kedudukannya sebagai penguasa. Hal tersebut mendorong khalifah Al-Manshur untuk bersikap keras dalam peneguhan kedudukan keuangan negara, disamping penumpasan musuh-musuh khalifah, sehingga masapemerintahannya ini juga dikenal sebagai masa yang penuh dengan kekerasan. Dalam mengendalikan harga-harga, khalifah al-Manshur memerintahkan para kepala jawatan pos untuk melaporkan harga pasarang dari setiap bahan makanan dan barang lainnya. Para walinya agar menurunkan harga-harga ketingkat semula. Disamping itu, khalifah Al-manshur juga sangat hemat dalam membelanjakan harta Baitul Mal. Ketika ia meninggal, kekayaan kas negara telah mencapai 810 dirham (Hasyimi, 1987).

Keberhasilan khalifah al-manshur dalam meletakkan dasardasar pemerintahan Daulah Abbasiyah memudahkan usaha para khalifah berikutnya untuk lebih fokus terhadap permasalahan ekonomi dan keuangan negara, sehingga peningkatan dan pengembangan taraf hidup rakyat dapat terjamin. Ketika AlMahdi (158-169) menjadi khalifah, keadaan negara telah stabil. Ia banyak menerapkan kebijakan yang menguntungkan rakyat banyak, seperti pembangunan tempat-tempat persinggahan para 


\section{JOURNAL OF SOCIAL SCIENCES \& HUMANITIES "ESTORIA" UNIVERSITAS INDRAPRASTA PGRI}

musafir haji, pembuatan kolam-kolam air bagi para kafilah dengan beserta hewan bawaannya, serta memperbaiki dan memperbanyak jumlah telaga dan perigi. Ia juga mengembalikan seluruh harta yang dirampas ayahnya kepada pemiliknya masing-masing.

Pada masa pemerintahan Al-Mahdi,perekonomian negara mulai meningkat dengan peningkatan di sektor pertanian melalui irigasi dan peningkatan hasil pertambangan, seperti emas, perak, tembaga dan besi. Di samping itu jalur transit perdagangan antara Timur dan Barat juga menghasilkan kekayaan. Dalam hal ini, basrah menjadi pelabuhan yang penting. Dengan demikian, setor-sektor pertanian yang menunjang kemakmuran Daulah Abbasiyah adalah pertanian, pertambangan dan perdagangan. Untuk meningkatkan sektor pertanian, pemerintah pengeluarkan berbagai kebijakan yang membela hak-hak kaum tani, seperti peringanan hasil pajak hasil bumi, penjaminan hak milik dan keselamatan jiwa, perluasan lahan pertanian di setiap daerah, dan pembangunan berbagai bendungan dan kanal. Sementara untuk meningkatkan sektor perdagangan, pemerintahh membuat sumur-sumur membangun tempat-tempat peristirahatan para kafilah dagang, dan mendirikan berbagai armada dagang serta menjaga keamanan pelabuhan dan pantai.

Ketika tampuk pemerintahan dikuasai khalifah Harun AlRasyid (70-193 H), pertumbuhan ekonomi berkembang dengan pesat dan kemakmuran Daulah Abbasiyah mencapai puncaknya. Pada masa pemerintahannya, khalifah Harun Al-rasyid melakukan diversifikasi sumber pendapatan negara. Ia membangun Baitul Mal untuk mengurus keuangan negara dengan menujuk seorang wajiz yang menjadi kepala beberapa diwan, yaitu:

a) Diwan al-khazanah, bertugas mengurus seluruh perbendaharaan negara.

b) Diwan al-Azra', bertugas mengurus kekayaan negara yangberupa hasil bumi.

c) Diwan Khazain Al-Silah, bertugas mengurus perlengkapan angkatan perang.

d) Sumber pendapatan pada masa pemerintahan ini adalah kharaj, jizyah, zakat, fai, ghanimah, usyr, dan harta lainnya. Seperti wakaf, sedekah dan harta warisan orang yang tidak mempunyai ahli waris. Seluruh pendapatan 
negara tersebut dimasukkan kedalam baitul Mall dan dikeluarkan berdasarkan kebutuhan pada masa pemerintahan Khalifah Harun Al-Rasyid, pendapatan Baitul Mal dialokasikan untuk riset ilmiah dan penterjemahan buku-buku Yunani, disamping untuk biaya pertahanan dan anggaran rutin pegawai. Pendapatan tersebut juga dialokasikan untuk membiayaai para tahanan dalam hal penyediaan makanan dan pakaian musim panas dan dingin (Amalia, 2010).

Pemerintahan Khalifah Harun Al-Rasyid juga sangat memperhatikan masalah perpajakan. Ia menunjuk Qadi Abu Yusuf untuk menyusun sebuah kitab pedoman mengenai keuangan secara syari'ah. Untuk itu, Imam Abu Yusuf menyusun kitab yang di beri judul kitab al-kharaj. Penulisan kitab Al Kharaj Abu Yusuf ini didasarkan perintah dan pertanyaan Khalifah Harun Ar Rasyid mengenai berbagai persoalan pajak (Karim, 2012). Pada masa Daulah Abbasiyah, sistem pemungutan alkharaj dilakukan dengan tiga cara, yaitu:

a) Al-muhassabah atau penaksiran luas areal tanah dan jumlah pajak yang harus dibayar dalam bentuk uang.

b) Al-Muqasamah atau penetapan jumlah tertentu (persentase) dari hasil yang diperoleh.

c) Al- Muqqatha'ah atau penetapan pajak hasil bumi terhadap para jutawan berdasarkan persetujuan antara pemerintah dengan yang bersangkutan

Sepeninggal Harun Al-Rasyid, tampuk pemerintahan Daulah Abbasiyah diserahkan kepada Khalifah Al-Ma'mun (198-218H). Pribadi AL-Ma'mun adalah pribadi yang sangat mencintai ilmu dan hal ini sangat mempengaruhi berbagai kebijakannya. Pada masa pemerintahannya, khalifah Al-Ma'mun memberikan perhatian yang besar terhadap pengembangan ilmu pengetahuan dalam Islam. Ia semakin menggalakkan aktifitas penerjemahan buku-buku asing. Untuk menunjang hal tersebut, pemerintah mengalokasikan dana Baitul Mal untuk gaji para penterjemah. Khalifah Al-Ma'mun juga mendirikan sekolah-sekolah dan yang termasyhur adalah Baitul Hikmah, pusat penerjemahan yang berfungsi sebagai perguruan tinggi dengan dilengkapi perpustakaan yang besar. Pada masa tersebut, baghdad mulai 
menjadi pusat kebudayaan dan ilmu pengetahuan. Dari gambaran diatas, terlihat bahwa Dinasti Bani Abbasiyah pada periode pertama lebih menekankan pembinaan peradaban dan kebudayaan Islam, termasuk kehidupan perekonomian, dari pada perluasan wilayah. Setelah melewati periode ini, Daulah Abbasiyah mengalami kemunduran dan akhirnya dihancurkan oleh bangsa Mongol pada tahun $1258 \mathrm{M}$.

\section{KESIMPULAN}

Perkembangan ekonomi islam pada Dinasti Umayyah dan Abbasiyah merupakan sebuah catatan sejarah yang dapat diambil pelajarannya. Sebuah sistem yang kuat tentunya di dukung pula oleh elemen-elemen lainnya, sehingga sebuah sistem itu dapat berjalan dengan baik. Terutama oleh penguasannya.

Masa kekhalifahan bani umayyah hanya berumur 90 tahun yaitu dimulai pada kekuasaan muawiyyah bin abu sofyan. Pemikiran ekonomi islam bani umayyah pada masa pemerintahan bani umayyah, kebijakan ekonomi banyak dibentuk berdasarkan ijtihad para fuqoha dan ulama sebagai konsekuensi semakin jauhna rentang waktu antara zaman kehidupan Rasulullah dan masa pemerintahan tersebut. Khalifah abbasiyah atau kekuasaan dinasti bani abbas, sebagai mana disebutkan melanjutkan kekuasaan dinasti bani umayah. Kekuasaannya berlangsung rentang waktu yang panjang . selama dinasti bani abbasiyah berkuasa dimana pola pemerintahan yang diterapkan berbeda-beda sesuain dengan perubahan politik, sosial, dan budaya.

\section{DAFTAR PUSTAKA}

Absor, N. F. (2019). PENGGUNAAN KONSTRUKSI DAN KONSENSUS DALAM KEBENARAN SEJARAH. Prosiding Seminar Nasional Penguatan Riset Dan Luarannya Sebagai Budaya Akademik Di Perguruan Tinggi Memasuki Era 5.0, 304-310.

Amalia, E. (2010). Sejarah Pemikiran Ekonomi Islam. Depok: Gramata.

Engineer, A. A. (1999). Asal Usul dan Perkembangan Islam. Yogyakarta: Pustaka Pelajar.

Hasyimi, A. (1987). Sejarah Kebudayaan Islam. Jakarta: Bulan 
Bintang.

Karim, A. A. (2012). Sejarah Pemikiran Ekonomi Islam. Depok:

Raja Grafindo Persada.

Zuhri, M. (1997). Hukum Islam dalam Lintasan Sejarah. Jakarta:

Rajawali Pers. 